University of Wollongong

Research Online

Faculty of Social Sciences - Papers (Archive) Faculty of Arts, Social Sciences \& Humanities

$1-1-2019$

Sports participation, health behaviours, and body fat during childhood and early adolescence: a multiple mediation

\author{
Stewart A. Vella \\ University of Wollongong, stvella@uow.edu.au \\ Lauren Gardner \\ University of Sydney, lag994@uowmail.edu.au \\ Byron Kemp \\ University of Wollongong, bjk687@uowmail.edu.au \\ Matthew Schweickle \\ University of Wollongong, mjs815@uowmail.edu.au \\ Dylan P. Cliff \\ University of Wollongong, dylanc@uow.edu.au
}

Follow this and additional works at: https://ro.uow.edu.au/sspapers

Part of the Education Commons, and the Social and Behavioral Sciences Commons

Research Online is the open access institutional repository for the University of Wollongong. For further information contact the UOW Library: research-pubs@uow.edu.au 


\title{
Sports participation, health behaviours, and body fat during childhood and early adolescence: a multiple mediation
}

\begin{abstract}
Objectives: The aim of this study was to simultaneously explore multiple pathways through which sports participation during childhood and adolescence may be associated with adiposity over time.

Design: Data were drawn from the Kindergarten cohort of the Longitudinal Study of Australian Children. A total of 4286 children provided sports participation data at age 10 years and were followed up 24 and 48 months later.

Method: Time spent in organised sports at age 10 years and time spent in physical activity at age 12 years were measured via parental-reported time-use diary. Dietary behaviours were self-reported at age 12 years. Screen time was parent-reported. Body fat was measured at age 14 using bioelectrical impedance analysis. Two parallel multiple mediation models were tested to examine the longitudinal associations between sport participation at age 10 and body fat at age 14 via the mediating variables of physical activity, screen time, and dietary behaviours. One model was run for all participants, and a second model was run only for those participants who reported participating in organised sports.
\end{abstract}

Results: There were no significant indirect relationships between sports participation and body fat via any of the mediating variables in the total sample, or among sport participants.

Conclusions: There is a dearth of evidence to support substantial rhetoric and policy to promote organised sports programs as public health initiatives in their current form during childhood and adolescence. Better quality evidence is needed, however, modifications to sport programs may be necessary to elucidate meaningful benefits for adiposity.

\section{Disciplines}

Education | Social and Behavioral Sciences

\section{Publication Details}

Vella, S. A., Gardner, L. A., Kemp, B., Schweickle, M. J. \& Cliff, D. P. (2019). Sports participation, health behaviours, and body fat during childhood and early adolescence: a multiple mediation. Journal of Science and Medicine in Sport, 22 (12), 1324-1329. 
2 Objectives: The aim of this study was to simultaneously explore multiple pathways through which sports participation during childhood and adolescence may be associated with adiposity over time.

4 Design: Data were drawn from the Kindergarten cohort of the Longitudinal Study of Australian

5 Children. A total of 4286 children provided sports participation data at age 10 years and were

6 followed up 24 and 48 months later.

7 Method: Time spent in organised sports at age 10 years and time spent in physical activity at age 12

8 years were measured via parental-reported time-use diary. Dietary behaviours were self-reported at 9 age 12 years. Screen time was parent-reported. Body fat was measured at age 14 using bioelectrical impedance analysis. Two parallel multiple mediation models were tested to examine the longitudinal associations between sport participation at age 10 and body fat at age 14 via the mediating variables of physical activity, screen time, and dietary behaviours. One model was run for all participants, and a second model was run only for those participants who reported participating in organised sports.

14 Results: There were no significant indirect relationships between sports participation and body fat via any of the mediating variables in the total sample, or among sport participants.

Conclusions: There is a dearth of evidence to support substantial rhetoric and policy to promote organised sports programs as public health initiatives in their current form during childhood and adolescence. Better quality evidence is needed, however, modifications to sport programs may be necessary to elucidate meaningful benefits for adiposity. 


\section{Sports Participation, Health Behaviours, and Body Fat during Childhood and Early}

\section{Adolescence: A Multiple Mediation}

Sports participation is one of the most popular and time consuming leisure activities for young people. Over $40 \%$ of all children and adolescents participate in organised sports in developed countries, with participation rates even higher among high-income countries ${ }^{1}$. This has led organisations such as the United Nations ${ }^{2}$, International Olympic Committee (IOC) $)^{3}$ and the World Health Organisation ${ }^{4}$ to promote sport participation as a population level health promotion strategy. The IOC, in particular, have articulated the importance of sport among young people: 'sport has an important role to play in the current global health crisis of rising morbidity and mortality from noncommunicable diseases caused by physical inactivity, already starting at a young age... and can be instrumental in invoking behaviour changes in young people to positively affect global health' ${ }^{3} \mathrm{p}$. 837).

Despite strong rhetoric and policy action (e.g., $\left.{ }^{5}\right)$, the evidence that sport participation is associated with better health outcomes during childhood and adolescence is equivocal ${ }^{6,7}$. In two systematic reviews, sports participation has been established as a correlate of higher levels of physical activity $^{6,7}$. Nonetheless, the relationship between sports participation and measures of adiposity was equivocal or non-existent. Recent evidence has suggested that the relationship between sports participation and adiposity may be bidirectional in nature ${ }^{8}$, which may in part account for equivocal findings. Nonethless, over reliance on cross-sectional studies, and an inability to account for the multiple ways in which sport may influence adiposity over time are primary limitations of the field. For example, while sports participation may be associated with higher levels of physical activity, it may also be associated with higher caloric intake ${ }^{6}$. Further, models of health through sport such as the conceptual model of health through sport ${ }^{9}$ and the settings based approach to health promotion through sport ${ }^{10}$ do not specify the causal pathways or behaviours through which sport may influence health over time. According to the Behavioral Epidemiology framework ${ }^{11}$, establishing the links between health behaviours and health outcomes is the foundational stage of epidemiological research.

Such knowledge is necessary before intervention research and research translation can occur. 
The aim of this study was to simultaneously explore multiple pathways through which sports participation during childhood and adolescence may be associated with adiposity over time. Using a longitudinal sample of Australian children, multiple mediations will be used to explore the simultaneous longitudinal associations and indirect effects of sports participation on measures of adiposity, via its association with subsequent obesity-related behaviours, including levels of physical activity, dietary behaviours, and screen time. Given strong cross-sectional associations between sports participation and physical activity ${ }^{6}$, and strong evidence that physical activity is associated with adiposity $^{12}$, we hypothesise that sports participation will be negatively associated with adiposity over time through increased physical activity. All other analyses are exploratory.

\section{Method}

Data were obtained from the Kindergarten (K) Cohort of the Longitudinal Study of Australian Children (LSAC). Commencing in 2004, the K Cohort of LSAC tracks the health and wellbeing of Australian children from 4 to 5 years of age, with follow-up data collected biennially. Families were randomly selected from the Australian Medicare database. At each time point, trained data collectors conducted structured face-to-face interviews with the child's primary parent (in $96 \%$ of cases this was the mother ${ }^{13}$ ), and collected parental-report questionnaires and child- and parent-reported time-use diaries (TUD). This study utilised data collected from Waves 4 (2010) to 6 (2014), covering a developmental period from ages 10 to 11 years until 14 to 15 years. For clarity, we refer to the ages of children as 10,12, and 14 years of age across the three waves, respectively. At Wave 4, 3994 participants had complete sports participation data via the child-reported TUD ${ }^{14}$. The research methodology and survey content of Growing Up in Australia is reviewed and approved by the Australian Institute of Family Studies Ethics Committee, which is a Human Research Ethics Committee registered with the National Health and Medical Research Council. Informed consent was obtained from all participants.

The duration of organised sports participation was reported by children at 10 years of age via the TUD instrument. Children were mailed an open-ended paper diary to complete on the day before their interview over a 24 -hour period ${ }^{15}$. These diaries were then transposed by interviewers according 
to a predetermined coding framework ${ }^{15}$. Interviewers were also trained to fill gaps in the diary by prompting the child for further information during the home interview. In the present study, two activity codes were aggregated to measure sports participation: "Organised team sports and training" and "Organised individual sports and training" 15 . The duration of time spent in these activity codes was calculated by one researcher (BK). Firstly, the duration of each activity was determined as the difference between the start time of the activity and the start time of the next activity in sequence for each child. It was assumed that the last activity of each child's day ended at the child's bed time. The total duration of organised sports participation was then aggregated for each participant, and is reported as total number of minutes. A similar process was used to create a dummy variable for school attendance (yes/no) based on the "School lessons" activity code. Finally, although children were allowed to record up to six activities concurrently in the TUD, sport participation was based on the primary activity selected at any one time. Unlike other activities such as eating or listening to music, organised sport seems less logical as a concurrent activity.

Indirect effects between sport participation and measures of adiposity were tested using the following mediating variables: time spent in physical activity; fruit and vegetable consumption; consumption of high fat foods; consumption of high sugar drinks; and, screen time.

The duration of physical activity was calculated from the TUD instrument completed by children at 12 years of age. The total time spent in physical activity was extracted from the TUD using the same process that was used to extract organised sports participation data. Fourteen activity codes were aggregated to form an overall measure of physical activity: "Organised team sports and training", "Organised individual sports and training", "Unstructured active play", "[Travel] by bike, scooter, skateboard, etc”, “[Travel] by foot”, "Pamphlet delivering”, "Umpiring/refereeing”, "Car washing", "Gardening / lawn mowing [paid]", "Gardening / lawn mowing [chore]", "Cleaning/tidying", "Walking pets/playing with pets", "Active club activities" and "Active activities (not elsewhere classifiable)". Compendia of Energy Expenditures for Youth ${ }^{16}$ and Adults ${ }^{17}$ were used to determine the Metabolic Equivalent of Task values of household chores and occupational tasks. These activity codes were considered to be physically active if they had a MET value of at least 3.0. 
102

To ensure consistency with the organised sports variable, the physical activity variable was based on the primary activity selected at any one time.

Children reported their consumption of fruit and vegetables at age 12 years using a summed total of three items. Participants were asked to report "Thinking about yesterday, how often did you have..." fresh fruit, cooked vegetables, and raw vegetables or salad? The three items were scored a 0 for 'Not at all', 1 for 'Once', 2 for 'Twice', and 3 for 'More than twice'.

Four self-reported items were used to assess children's consumption of high fat foods at age 12 years. Children were asked "Thinking about yesterday, how often did you have..." (i) meat pie, hamburger, hot dog, sausage, or sausage roll; (ii) hot chips or french fries; (iii) potato chips or savoury snacks such as 'Twisties'; and, (iv) biscuits, doughnut, cake or chocolate. All items were scored a 0 for 'Not at all', 1 for 'Once', 2 for 'Twice', and 3 for 'More than twice'. Total serves were computed using the sum of all four items.

A single item was used to assess consumption of high sugar drinks. Participants were asked “Thinking about yesterday, how often did you have soft drink or cordial?". The item was scored a 0 for 'Not at all', 1 for 'Once', 2 for 'Twice', and 3 for 'More than twice'.

Parents reported children's time spent watching TV and playing electronic games at age 12 years using a total of four items. Parents were asked "About how many hours on a typical weekday does (your child) spend..." and "About how many hours on a typical weekend day does (your child) spend..." for both watching television and playing electronic games. A weighted weekly average was calculated by multiplying the average weekday use by 5 and the average weekend day use by 2 , and then these were summed to provide a weighted weekly average for watching television and playing electronic games. The two weighted weekly averages were then summed to represent total weekly screen time. Body fat percentage was used as a measure of adiposity. Body fat percentage was measured on digital scales using bioelectrical impedance analysis at all Waves.

Covariates were assessed at Wave 4 when children were aged 10 years, and included child sex and neighbourhood socioeconomic position (SEP). Neighbourhood SEP was determined 
according to the Socio-Economic Indexes for Areas Index of Relative Socio-Economic Disadvantage ${ }^{18}$ using the child's home postcode. In addition, day of the week and school attendance (yes/no) were used as covariates for the sport participation variable measured by TUD.

Two parallel multiple mediation path models were tested to examine the longitudinal associations between sport participation at age 10 (independent variable) and adiposity at age 14 (dependent variable), via physical activity, fruit and vegetable consumption, consumption of high fat foods, consumption of high sugar drinks, and screen time at age 12 (mediating variables). This approach allows for the modelling of multiple mechchanisms simultaneously, while also allowing the mediators (in this case the various health behaviours) to be correlated. The multiple mediation approach has been outlined by Hayes ${ }^{19}$. A diagram of the parallel multiple mediation model is given in Figure 1. First the indirect path linking sport participation at age 10 with body fat percentage at age 14, via physical activity, fruit and vegetable consumption, consumption of high fat foods, consumption of high sugar drinks, and screen time at age 12, was tested among all participants, controlling for all mediating variables at age 10, body fat at age 10, child sex, household income, day of the week that the time-use diary was completed, and whether the child attended school that day. As a majority of participants reported no sports participation (i.e., they reported 0 minutes per week), this analysis was subsequently repeated using only those participants that reported some level of sports participation at age 10 years ( $>0$ minutes per week). Finally, both of these analyses were repeated as sensitivity analyses after removing sport participation from the measure of physical activity as a mediating variable, to allow for any potential confounding between the predictor variable (sport participation) and the mediating variable (physical activity). Missing data were estimated using the full information maximum likelihood (FIML) method. A bootstrapping procedure with 5000 resamples was used to test the indirect effects, with significance determined from $95 \%$ confidence intervals. Results are presented as unstandardised $\beta$ coefficients. Analyses were conducted using Mplus version 7. Both models controlled for all covariates. 
Table 1 presents mean body fat percentage and covariate data over the total sample and by selected demographic variables. In total, 292 participants were missing organised sport participation data at age 10 years. Those with missing sport participation data at age 10 years lived in neighbourhoods with greater socioeconomic disadvantage ( $t=6.07, \mathrm{df}=4166, p<0.001)$, consumed less serves of fruit and vegetables $(t=2.59, \mathrm{df}=3842, p=0.003)$, and consumed greater serves of high fat food $(t=-2.39, \mathrm{df}=3842, p=0.017)$.

\section{(INSERT TABLE 1 HERE)}

The results of the first multiple mediation path model linking sport participation at age 10 to body fat at age 14 among all participants are illustrated in Table 2 . Sport participation at age 10 was positively associated with physical activity and fruit and vegetable consumption at age 12 , and negatively associated with consumption of high fat food and screen time at age 12 , after controlling for the covariates listed above. However, none of the mediating variables were significantly associated with body fat at age 14 . The direct effect of sport participation at age 10 on body fat at age 14 was not significant, $(\beta=.007, p=0.53)$, and there were no significant indirect relationships. Overall, the model was not a good fit for the data $(\mathrm{RMSEA}=.14 ; \mathrm{SRMR}=.09 ; \mathrm{CFI}=.46 ; \mathrm{TLI}=-$ $.32)$.

The results of the second multiple mediation path model linking sport participation at age 10 to body fat at age 14 among only those who reported sport participation are given in Table 2 . Greater sport participation at age 10 was positively associated with physical activity at age 12 after controlling for covariates. None of the mediating variables were significantly associated with body fat at age 14 . The direct effect of sport participation at age 10 on body fat at age 14 was not significant, $(\beta=-.006$, $p=0.78$ ), and there were no significant indirect relationships. Overall, the model was not agood fit for the data $(\mathrm{RMSEA}=.15 ; \mathrm{SRMR}=.10 ; \mathrm{CFI}=.43 ; \mathrm{TLI}=-.39)$.

\section{(INSERT TABLE 2 HERE)}

Sensitivity analyses following removal of sport participation from the mediating physical activity variable showed no meaningful change in results in either model. Results are reported in 
Table 3. Among all participants, the direct effect of sport participation at age 10 on body fat at age 14 was not significant, $(\beta=.003, p=0.774)$, and there were no significant indirect relationships. Overall, the model was not a good fit for the data $(\mathrm{RMSEA}=.12 ; \mathrm{SRMR}=.08 ; \mathrm{CFI}=.52 ; \mathrm{TLI}=-.17)$. Among sport participants, the direct effect of sport participation at age 10 on body fat at age 14 was not significant, $(\beta=.000, p=0.981)$, and there were no significant indirect relationships. Overall, the model was not a good fit for the data $(\mathrm{RMSEA}=.12 ; \mathrm{SRMR}=.09 ; \mathrm{CFI}=.43 ; \mathrm{TLI}=-.39)$. In both models, sport participation at age 10 was no longer associated with physical activity at age 12 .

\section{(INSERT TABLE 3 HERE)}

\section{Discussion}

The aim of this study was to simultaneously explore multiple pathways through which sports participation during childhood and adolescence may be associated with adiposity over time. Although sports participation at age 10 years was positively associated with physical activity and fruit and vegetable consumption, and negatively associated with consumption of high fat foods and screen time at age 12 years, the direct effects of sport participation at age 10 on adiposity at age 14 were not significant, and there were no significant indirect relationships. As such, in this study sports participation was neither directly associated with adiposity four years later, nor indirectly linked through its association with health behaviours.

Despite the implementation of health policies based on organised sports participation ${ }^{2-5}$, the evidence to support the long term health benefits of sports participation during childhood and adolescence for levels of adiposity is equivocal. On this basis, criticisms of the promotion of sport as a public health initiative have recently emerged ${ }^{17}$. This study offers no further evidence to support the use of organised sports, in their current form, for the prevention of non-communicable diseases such as obesity. Some reasons for this may include the low mean time spent in organised sports $(\sim 25$ mins. $\mathrm{wk}^{-1}$ in this study), low levels of moderate to vigorous physical activity during sports participation ${ }^{20-22}$, and high dropout rates from organised sports during late childhood and adolescence $^{23}$. Some limited evidence from controlled trials does suggest that sport participation can 
lead to decreases in adiposity when implementation is highly controlled ${ }^{24}$, but in their current form, participation in organised sports as delivered in community settings is unlikely to be associated with the prevention of major public health problems such as obesity ${ }^{6,7}$.

In contrast to the evidence on adiposity, the evidence to support the relationship between sports participation and higher levels of physical activity is reasonably conclusive $e^{6,7}$. This study suggests that these relationships can hold over a period of up to two years. Further, this study also suggests that sports participation predicts lower levels of screen time - a relationship previously documented in cross-sectional studies ${ }^{25}$. The Global Advocacy for Physical Activity has identified organised sports programs as one of the best investments for physical activity worldwide ${ }^{26}$. Policy in this area is justified by the body of evidence, however, relationships may not be strong. This may be because sports participation typically only includes between $20 \%$ and $50 \%$ of time spent in moderate to vigorous physical activity ${ }^{20-22}$. Further, the lack of experimental evidence prohibits assertions of causality ${ }^{6,7}$, and this is also true of the current study.

While sports participation at age 10 was associated with healthier lifestyle behaviours at age 12 years including greater physical activity, greater fruit and vegetable consumption, lesser consumption of high fat foods, and lesser screen time, it is unclear why these behaviours were not associated with measures of adiposity at age 14 years. For example, physical activity is associated with reduced adiposity during childhood, as is consumption of high fat foods ${ }^{12,27}$. However, the evidence is not strong for the influence of sedentary behaviours on adiposity during childhood ${ }^{28}$. It is currently unclear if the lack of association between participation in organised sports and measures of adiposity is due to the weak relationships between sports participation and health behaviours, or because the health behaviours themselves are not associated with measures of adiposity in this sample. This is an important differentiation because sports programs may legitimately be promoted as public health programs if they influence health behaviours over a number of years. However, if this influence is weak, or if the health behaviours themselves do not translate into reduced levels of adiposity, then organised sports programs may not be legitimately held up as programs for public health, at least when reduced adiposity is the desired outcome. 
The use of a large, longitudinal sample is a strength of the current study, as is the use of

234

235

236

237 multiple mediation pathways. Multiple mediation pathways are particularly important when the mediating variables may be related ${ }^{29}$. Limitations of the study include the 24-month time lag between Waves which may obscure meaningful short-term associations between variables. Likewise, the longitudinal nature of the study precludes inferences regarding causality. Further, an inability to differentiate between types of organised sport participation limits conclusions to those pertaining to organised sports as a whole. However, different sports programs and different age groups may have very different effects on health and health behaviours ${ }^{22}$. Whether participants maintained sports participation over the 48 months from which data were drawn may influence subsequent health behaviours and adiposity, however, this was not accounted for in the analyses. The use of a 24-hour recall time-use diary may also limit the study by virtue of missing some sport participation. A 7-day recall period would help to ameliorate this concern. Lastly, sports participation may influence a wide range of health behaviours beyond those included in this study. It is possible that by not accounting for behaviours such as alcohol consumption, this study misses an important causal pathway between sports participation and subsequent health.

In conclusion, we have explored the simultaneous pathways through which sports participation at age 10 years may be associated with measures of adiposity at age 14 years. There was no direct or indirect effect of sports participation on subsequent adiposity, although sports participation did beneficially predict some health behaviours at age 12 years, namely higher physical activity, greater fruit and vegetable intake, lesser consumption of high fat foods, and lesser screen time. There is a dearth of evidence to support substantial rhetoric and policy to promote organised sports programs as public health initiatives in their current form, at least in regards to levels of adiposity. Better quality evidence is needed, however, limited experimental research suggests that when implemented in a controlled environment, sports programs can have meaningful benefits to adiposity among young people. 
- Sport participation is positively associated with healthy behaviours, and negatively associated with unhealthy behaviours, at a later age.

- Sport participation has no association with body fat at later age

- Policy makers should consider the design and implementation of sports programs to best address public health issues

\section{Acknowledgements}

The Longitudinal Study of Australian Children is conducted in partnership between the Department of Families, Housing, Community Services and Indigenous Affairs (FaHCSIA), the Australian Institute of Family Studies (AIFS) and the Australian Bureau of Statistics (ABS). They were responsible for the design and conduct of the study, and the collection and management of data. The findings and views reported in this paper are those of the authors and should not be attributed to FaHCSIA, AIFS or the ABS.

Funding: The first author is supported by a National Heart Foundation of Australia Postdoctoral Fellowship (100974). 
275 1. Tremblay MS, Barnes JD, Gonzalez SA, et al. Global Matrix 2.0: Report Card Grades on the Physical Activity of Children and Youth Comparing 38 Countries. Journal of Physical Activity and Health 2016; 13:S343-S366.

2. United Nations Inter-Agency Task Force. Sport for Development and Peace: Towards achieving the Millennium Development Goals, New York2003.

3. Mountjoy M. Health and fitness of young people: What is the role of sport? British Journal of Sports Medicine 2011; 45:837-838.

4. World Health Organisation. Promoting sport and enhancing health in European

5. Cabinet Office. Sporting future: a new strategy for an active nation. London, 2015.

6. Nelson TF, Stovitz SD, Thomas M, LaVoi NM, Bauer KW, Neumark-Sztainer D. Do Sports Medicine Reports 2011; 10:360-370.

7. Lee JE, Pope Z, Gao Z. The role of youth sports in promoting children's physical activity and preventing pediatric obesity: A systematic review. Behavioral Medicine $2018 ; 44: 62-76$.

8. Cairney J, Veldhuizen S. Organized sport and phsyical activity participation and body mass index in children and youth: A longitudinal study. Preventive Medicine Reports 2017; 6:336-338.

9. Eime RM, Young JA, Harvey JT, Charity MJ, Payne, WR. A systematic review of the psychological and social benefits of participation in sport for children and adolescents: informing development of a conceptual model of health through sport. International Journal of Behavioral Nutrition and Physical Activity 2013; 10:98. 
10. Kokko S. Sports clubs as settings for health promotion: Fundamentals and an overview of research. Scandinavian Journal of Public Health 2014; 42(Supp. 15):6065.

11. Sallis JF, Owen N, Fotheringham MJ. Behavioral epidemiology: a systematic framework to clasify phases of research on health promtion and disease prevention. Annals of Behavioral Medicine 2000;22:294-298.

12. Janssen I, LeBlanc AG. Systematic review of the health benefits of physical activity and fitness in school-aged children and youth. International Journal of Behavioral Nutrition and Physical Activity 2010; 7.

13. Edwards B. Growing Up in Australia: The Longitudinal Study of Australian Children: The first decade of life. Family Matters 2012; 91:7-17.

14. Australian Institute of Family Studies. Longitudinal Study of Australian Children Data User Guide - November 2015. Melbourne, Australia, 2015.

15. Corey J, Gallagher J, Davis E, Marquardt M. The Times of Their Lives: Collecting time use data from children in the Longitudinal Study of Australian Children (LSAC). Canberra 2014.

16. Ridley K, Ainsworth BE, Olds TS. Development of a compendium of energy expenditures for youth. International Journal of Behavioral Nutrition and Physical Activity 2008; 5:45.

17. Ainsworth BE, Haskell WL, Herrmann SD, et al. Compendium of Physical Activities: a second update of codes and MET values. Medicine and Science in Sports and Exercise 2011; 43:1575-1581.

18. Australian Bureau of Statistics. Information paper. An introduction to SocioEconomic Indexes for Areas (SEIFA) 2006. Catalogue no. 2039.0. Canberra: Australian Bureau of Statistics; 2008. 
19. Hayes AF. Introduction to mediation, moderation, and conditional process analysis: a regression-based approach. New York, NY: The Guildford Press; 2013.

20. Guagliano J, Rosenkranz R, Kolt G. Girls' physical activity levels during organised sports in Australia. Medicine and Science in Sports and Exercise 2013; 45:116-122.

21. Wickel EE, Eisenmann JC. Contribution of youth sport to total daily physical activity among 6- to 12-year old boys. Medicine and Science in Sports and Exercise 2007; 39:1493-1500.

22. Leek D, Carlson JA, Cain KL, et al. Physical activity during youth sport practices. Archives of Pediatric and Adolescent Medicine. 2011; 165:294-299.

23. Balish SM, McLaren C, Rainhaim D, Blanchard C. Correlates of youth sport attrition: a review and future directions. Psychology of Sport and Exercise. 2014; 15:429-439.

24. Weintraub DL, Tirumalai EC, Haydel F, Fujimoto M, Fulton JE, Robinson TN. Team sports for overweight children: The Stanford Sports to Prevent Obesity randomized trial. Archives of Pediatric and Adolescent Medicine 2008; 162:232-237.

25. Vella SA, Cliff DP, Okely AD, Scully M, Morley B. Associations between organized sports participation and obesity-related health behaviors in Australian adolescents. International Journal of Behavioral Nutrition and Physical Activity 2013; 10:113.

26. Global Advocacy for Physical Activity (GAPA) the Advocacy Council of the International Society for Physical Activity and Health (ISPAH). NCD prevention: Investments that work for physical activity. British Journal of Sports Medicine 2012; 46:709-712.

27. Rosenheck R. Fast food consumption and increased caloric intake: a systematic review of a trajectory towards weight gain and obesity risk Obesity Reviews 2008; 9:535-547. 
347 28. Cliff DP, Hesketh KD, Vella SA, et al. Objectively measured sedentary behaviour and health and development in children and adolescents: systematic review and metaanalysis. Obesity Research 2016; 17:330-344.

350 29. VanderWeele TJ, Vansteelandt S. Mediation analysis with multiple mediators. Epidemiol Method 2014; 2:95-115. 
353 Mean body fat percentage and covariate data over the total sample and by selected demographic variables.

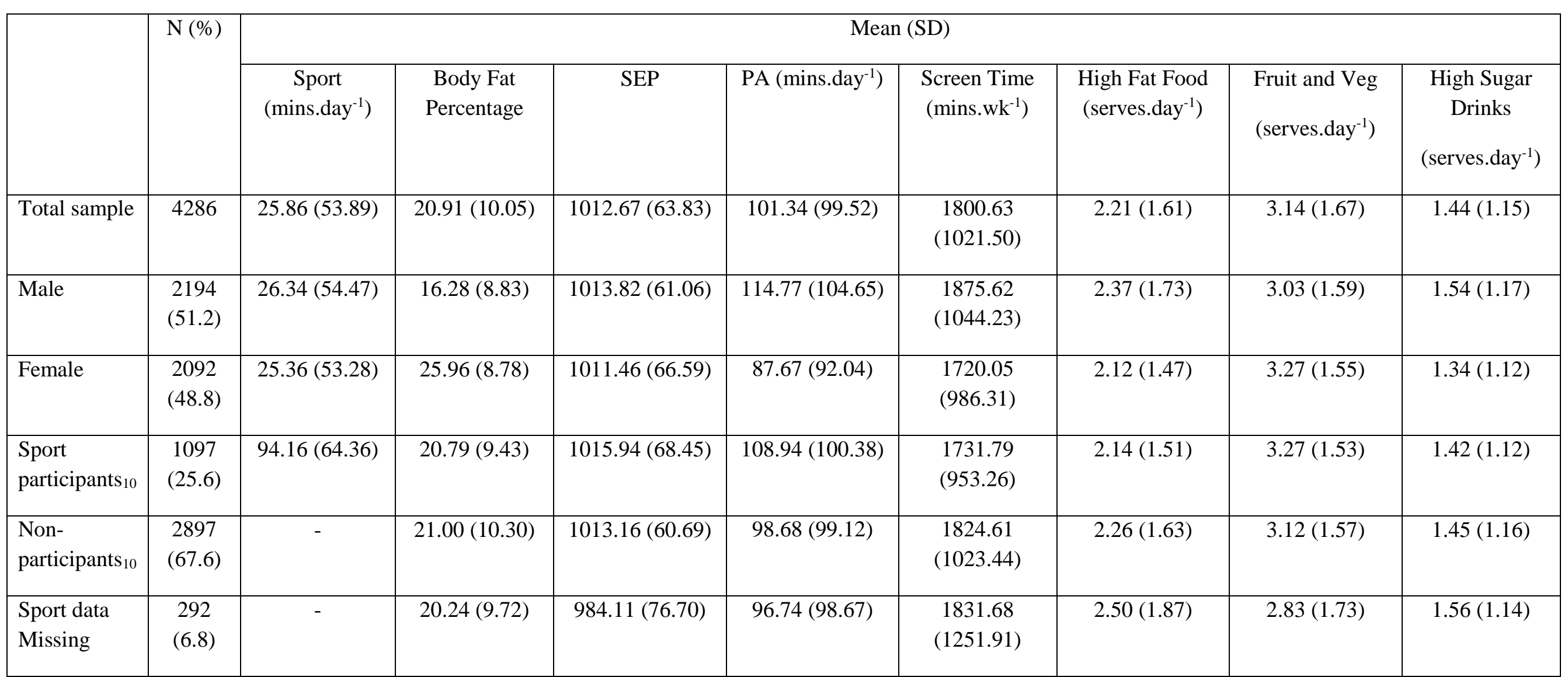

354 Note. $\mathrm{SEP}=$ Socioeconomic position as measured by the Socio-Economic Index for Areas; PA = Physical activity; Veg = Vegetables 
Table 2 .

357 Unstandardised results of the multiple mediation path model linking sport participation at age 10 to

358 body fat at age 14.

\begin{tabular}{|c|c|c|c|c|c|c|}
\hline & \multicolumn{3}{|c|}{ All Participants } & \multicolumn{3}{|c|}{ Sport Participants } \\
\hline & $\beta$ & SE & $95 \% \mathrm{CI}$ & $\beta$ & SE & $95 \% \mathrm{CI}$ \\
\hline \multicolumn{7}{|l|}{ a paths } \\
\hline Sport $_{10} \rightarrow$ Physical Activity $_{12}$ & $.079 *$ & 017 & $.045, .113$ & $.093^{*}$ & .029 & $.036, .168$ \\
\hline Sport $_{10} \rightarrow$ Fruit $\&$ Vegetable $_{12}$ & $.021 *$ & .011 & $.001, .041$ & .009 & .017 & $-.026, .050$ \\
\hline Sport $_{10} \rightarrow$ High Fat Diet 12 & $-.022 *$ & .009 & $-.040,-.007$ & -.015 & .014 & $-.042, .013$ \\
\hline Sport $_{10} \rightarrow$ High Sugar Drinks 12 & -.008 & .007 & $-.019, .006$ & -.004 & .011 & $-.027, .018$ \\
\hline Sport $_{10} \rightarrow$ Screen Time $_{12}$ & $-.033 *$ & .013 & $-.057,-.012$ & -.022 & .019 & $-.059, .016$ \\
\hline \multicolumn{7}{|l|}{ b paths } \\
\hline Physical Activity $_{12} \rightarrow$ Body Fat 14 & -.016 & .015 & $-.045, .014$ & -.056 & .030 & $-.118, .001$ \\
\hline Fruit $\&$ Vegetable $_{12} \rightarrow$ Body Fat 14 & -.014 & .023 & $-.058, .032$ & .031 & .047 & $-.118, .123$ \\
\hline High Fat Diet $_{12} \rightarrow$ Body Fat $_{14}$ & -.019 & .023 & $-.066, .025$ & -.087 & .045 & $-.177, .003$ \\
\hline High Sugar Drinks $_{12} \rightarrow$ Body Fat $_{14}$ & .012 & .032 & $-.049, .073$ & -.051 & .059 & $-.168, .063$ \\
\hline Screen Time $_{12} \rightarrow$ Body Fat $_{14}$ & .008 & .016 & $-.023, .040$ & .024 & .031 & $-.032, .090$ \\
\hline \multicolumn{7}{|l|}{ Indirect effect } \\
\hline Sport $_{10} \rightarrow$ Physical Activity $_{12} \rightarrow$ Body Fat $_{14}$ & -.001 & .001 & $-.004, .001$ & -.005 & .003 & $-.014, .001$ \\
\hline Sport $_{10} \rightarrow$ Fruit $\&$ Vegetable $_{12} \rightarrow$ Body Fat 14 & .000 & .001 & $-002, .001$ & .000 & .001 & $-.001, .004$ \\
\hline Sport $_{10} \rightarrow$ High Fat Diet ${ }_{12} \rightarrow$ Body Fat $_{14}$ & .000 & .001 & $-.001, .002$ & .001 & .002 & $-.001, .006$ \\
\hline Sport $_{10} \rightarrow$ High Sugar Drinks $12 \rightarrow$ Body Fat $_{14}$ & .000 & .000 & $-.001, .000$ & .000 & .001 & $-.001, .004$ \\
\hline Sport $_{10} \rightarrow$ Screen Time $_{12} \rightarrow$ Body Fat $_{14}$ & .000 & .001 & $-.002, .000$ & -.001 & .001 & $-.004, .001$ \\
\hline \multicolumn{7}{|l|}{ Covariates } \\
\hline Body Fat $_{10} \rightarrow$ Body Fat 14 & $.206^{*}$ & .019 & $.170, .243$ & $.165^{*}$ & .027 & $.115, .222$ \\
\hline Physical Activity $_{10} \rightarrow$ Body Fat $_{14}$ & -.006 & .014 & $-.034, .021$ & .020 & .030 & $-.044, .086$ \\
\hline Fruit $\&$ Vegetable $_{10} \rightarrow$ Body Fat $_{14}$ & .009 & .017 & $-.025, .043$ & -.001 & .047 & $-.062, .065$ \\
\hline High Fat Diet $_{10} \rightarrow$ Body Fat 14 & .004 & .019 & $-.034, .039$ & .024 & .045 & $-.039, .084$ \\
\hline High Sugar Drinks $_{10} \rightarrow$ Body Fat $_{14}$ & .024 & .028 & $-.035 . .077$ & .021 & .059 & $-.080, .110$ \\
\hline Screen Time $_{10} \rightarrow$ Body Fat $_{14}$ & $.113^{*}$ & .026 & $.065, .167$ & .065 & .031 & $-.004, .137$ \\
\hline Sex $\rightarrow$ Body Fat 14 & $1.875^{*}$ & .071 & $\begin{array}{l}1.733 \\
2.008\end{array}$ & $1.912 *$ & .126 & $\begin{array}{c}-1.661 \\
2.154 \\
\end{array}$ \\
\hline Neighbourhood $\mathrm{SEP}_{10} \rightarrow$ Body Fat $_{1}$ & -.015 & .016 & $-.048, .016$ & $-.065^{*}$ & .030 & $-.131,-.012$ \\
\hline
\end{tabular}

359 Note. *Significant as per $95 \%$ bias-corrected confidence intervals estimated through 5000

360 bootstrapped resamples; Subscript numerals indicate child age. 
Table 3.

363 Unstandardised results of the sensitivity analyses linking sport participation at age 10 to body fat at 364 age 14 following removal of sport participation from the physical activity variable.

\begin{tabular}{|c|c|c|c|c|c|c|}
\hline & \multicolumn{3}{|c|}{ All Participants } & \multicolumn{3}{|c|}{ Sport Participants } \\
\hline & $\beta$ & SE & $95 \% \mathrm{CI}$ & $\beta$ & $\mathrm{SE}$ & $95 \% \mathrm{CI}$ \\
\hline \multicolumn{7}{|l|}{ a paths } \\
\hline Sport $_{10} \rightarrow$ Physical Activity $_{12}$ & .012 & .016 & $-.019, .045$ & .017 & .028 & $-.035, .072$ \\
\hline Sport $_{10} \rightarrow$ Fruit $\&$ Vegetable $_{12}$ & $.021 *$ & .011 & $.001, .041$ & .009 & .017 & $-.026, .039$ \\
\hline Sport $_{10} \rightarrow$ High Fat Diet 12 & $-.022 *$ & .009 & $\begin{array}{l}-.040,- \\
.004\end{array}$ & -.015 & .014 & $-.042, .013$ \\
\hline Sport $_{10} \rightarrow$ High Sugar Drinks 12 & -.006 & .007 & $-.019, .008$ & -.004 & .011 & $-.027, .017$ \\
\hline Sport $_{10} \rightarrow$ Screen Time $_{12}$ & $-.033^{*}$ & .013 & $\begin{array}{l}.057,- \\
.0008\end{array}$ & -.022 & .019 & $-.059, .016$ \\
\hline \multicolumn{7}{|l|}{ b paths } \\
\hline Physical Activity $_{12} \rightarrow$ Body Fat $_{14}$ & -.012 & .017 & $-.046, .022$ & -.045 & .036 & $-.115, .023$ \\
\hline Fruit $\&$ Vegetable $12 \rightarrow$ Body Fat 14 & -.014 & .023 & $-.058, .032$ & .031 & .047 & $-.062, .123$ \\
\hline High Fat Diet $_{12} \rightarrow$ Body Fat $_{14}$ & -.019 & .023 & $-.065, .025$ & -.084 & .045 & $-.174, .004$ \\
\hline High Sugar Drinks $_{12} \rightarrow$ Body Fat $_{14}$ & .011 & .032 & $-.049, .073$ & -.049 & .059 & $-.167, .067$ \\
\hline Screen Time $_{12} \rightarrow$ Body Fat $_{14}$ & .009 & .016 & $-.023, .041$ & .025 & .032 & $-.032, .092$ \\
\hline \multicolumn{7}{|l|}{ Indirect effect } \\
\hline $\begin{aligned} \text { Sport }_{10} & \rightarrow \text { Physical Activity }_{12} \rightarrow \\
\text { Body Fat }_{14} & \rightarrow\end{aligned}$ & .000 & .001 & $-.004, .001$ & -.001 & .002 & $-.007, .001$ \\
\hline 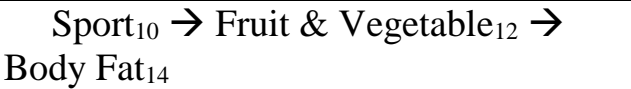 & .000 & .000 & $-002, .001$ & .000 & .001 & $-.001, .004$ \\
\hline $\begin{array}{l}\quad \text { Sport }_{10} \rightarrow \text { High Fat Diet } 12 \\
\text { Fat }_{14}\end{array}$ & .000 & .001 & $-.001, .002$ & .001 & .002 & $-.001, .006$ \\
\hline $\begin{aligned} \text { Sport }_{10} & \rightarrow \text { High Sugar Drinks } \\
12 & \rightarrow \\
\text { Body Fat }_{14} & \rightarrow\end{aligned}$ & .000 & .001 & $-.001, .000$ & .000 & .001 & $-.001, .003$ \\
\hline $\begin{array}{l}\quad \text { Sport }_{10} \rightarrow \text { Screen Time }_{12} \rightarrow \text { Body } \\
\text { Fat }_{14}\end{array}$ & .000 & .001 & $-.002, .000$ & -.001 & .001 & $-.004, .001$ \\
\hline \multicolumn{7}{|l|}{ Covariates } \\
\hline Body Fat $_{10} \rightarrow$ Body Fat 14 & $.206^{*}$ & 019 & $.170, .244$ & $.166^{*}$ & .028 & $.116, .222$ \\
\hline Physical Activity $_{10} \rightarrow$ Body Fat $_{14}$ & -.009 & .017 & $-.035, .021$ & .017 & .033 & $-.048, .083$ \\
\hline Fruit $\&$ Vegetable $_{10} \rightarrow$ Body Fat $_{14}$ & .009 & .017 & $-.025, .043$ & -.001 & .032 & $-.063, .065$ \\
\hline High Fat Diet $_{10} \rightarrow$ Body Fat $_{14}$ & .004 & .019 & $-.034, .039$ & .023 & .031 & $-.039, .084$ \\
\hline High Sugar Drinks $_{10} \rightarrow$ Body Fat $_{14}$ & .017 & .020 & $-.035, .076$ & .019 & .049 & $-.082, .108$ \\
\hline Screen Time $_{10} \rightarrow$ Body Fat $_{14}$ & $.089 *$ & .020 & $.066, .168$ & .068 & .036 & $.000, .140$ \\
\hline Sex $\rightarrow$ Body Fat $_{14}$ & $.467^{*}$ & .071 & $\begin{array}{l}1.733, \\
2.012 \\
\end{array}$ & $1.926^{*}$ & .127 & $\begin{array}{r}-1.668 \\
2.168\end{array}$ \\
\hline Neighbourhood SEP $_{10} \rightarrow$ Body Fat $_{14}$ & -.013 & .015 & $-.048, .016$ & $-.066^{*}$ & .031 & $\begin{array}{l}-.134,- \\
.014\end{array}$ \\
\hline
\end{tabular}

365 Note. *Significant as per $95 \%$ bias-corrected confidence intervals estimated through 5000 